\title{
Vasopressor choice for hypotension in elective Cesarean section: ephedrine or phenylephrine?
}

Chandrakala P. Gunda ${ }^{1}$, Jennifer Malinowski², Aruna Tegginmath ${ }^{1}$, Venkatesh G. Suryanarayana ${ }^{1}$, Sathees B.C. Chandra²

\author{
${ }^{1}$ Krishna Rajendra Hospital and Cheluvamba Hospital, Mysore Medical College, Rajiv \\ Gandhi University, India \\ 2Department of Biological, Chemical and Physical Sciences, Roosevelt University, Chicago, \\ IL, USA
}

Submitted: 14 August 2009

Accepted: 17 December 2009

Arch Med Sci 2010; 6, 2: 257-263

DOI: 10.5114/aoms.2010.13905

Copyright (c) 2010 Termedia \& Banach

\section{Abstract}

Introduction: Hypotensive episodes are a common complication of spinal anesthesia during Cesarean section. The purpose of this study was to compare the effectiveness and the side effects of vasopressors, ephedrine and phenylephrine, administered for hypotension during elective Cesarean section under spinal anesthesia.

Material and methods: The study consisted of 100 selected ASA I/II females scheduled for elective Cesarean section under spinal anesthesia. Each patient was randomly assigned to one of the two double-blind study groups. Group $\mathrm{E}$ received $1 \mathrm{ml}$ ephedrine $(5 \mathrm{mg} / \mathrm{ml})$ with normal saline if hypotension was present $(n=50)$. Group P received $1 \mathrm{ml}$ phenylephrine $(100 \mu \mathrm{g} / \mathrm{ml})$ with normal saline if hypotension developed $(n=50)$. Heart rate $(\mathrm{HR})$, systolic blood pressure (SBP), diastolic blood pressure (DBP), mean arterial pressure (MAP) were compared within and between groups to basal levels at time increments of $0,2,4,6,8$, $10,15,20,25,30,45$, and 60 min from start of surgery. Incidence of side effects and neonatal outcomes were studied between groups.

Results: All patients required vasopressor therapy for hypotension. Administration of phenylephrine was associated with significant drop in HR. Changes in SBP, DBP, and MAP were similar in both groups for most observed times. The incidences of nausea/vomiting and tachycardia were significantly higher in the ephedrine group.

Conclusions: Phenylephrine and ephedrine are acceptable choices to combat maternal hypotension related to spinal anesthesia in elective Cesarean section. Complications of intra-operative nausea and vomiting, tachycardia and bradycardia should be considered when choosing a vasopressor, suggesting phenylephrine may be more appropriate when considering maternal well-being.

Key words: ephedrine, phenylephrine, spinal anesthesia, Cesarean section.

\section{Introduction}

Cesarean section is one of the most commonly performed operations. Many countries have seen increases in their rates due to factors such as widespread use of fetal monitoring, high private insurance rates, restrictive insurance policies, advancing maternal age and high medical malpractice costs [1-4]. With the large number of women undergoing this procedure, it is necessary to consider the inherent risks involved for both mother and child. General anesthesia has generally fallen out of favor in the international community for elective Cesarean sections. Increased risk to

\author{
Corresponding author: \\ Assoc. Prof. Sathees B.C. \\ Chandra, PhD \\ Department of Biological, \\ Chemical \\ and Physical Sciences \\ Roosevelt University \\ 430 S Michigan Avenue \\ Chicago, IL 60605, USA \\ Phone: 847-619-7968 \\ Fax: 847-619-8555 \\ E-mail: \\ schandra@roosevelt.edu
}


the fetus from the anesthetic drugs, maternal airway management and post-operative effects are well documented, though it is still used for emergency surgery [5-8]. Avoidance of the risks inherent in general anesthesia is crucial for improved maternal and fetal outcome [6,9].

Regional anesthesia in Cesarean section offers significant benefit over general anesthesia. Epidural anesthesia provides the opportunity to extend surgical anesthesia to post-surgical analgesia via catheter and control of the level of anesthesia. Spinal anesthesia is inexpensive and yields symmetric block rapidly. Combined spinal-epidural anesthesia offers the benefit of both epidural and spinal techniques with less medication, better reliability and less incidence of hypotension [10, 11]. However, regional anesthesia in Cesarean section is not without complication. Supine hypotension syndrome due to aortocaval compression could deteriorate the hemodynamic effect of spinal anesthesia [12, 13]. The risk to the mother includes symptoms of dizziness, nausea and vomiting due the rapid decline in blood pressure, while fetal acidosis may be among the fetal consequences of prolonged maternal hypotension $[11,14]$. To prevent injury to mother or fetus caused by hypotension, it is customary to treat supine hypotension syndrome quickly and efficiently.

Routinely, vasopressors such as ephedrine, metaraminol, and phenylephrine have been given prophylactically and preoperatively to combat maternal hypotension [15-18]. Until recently, ephedrine has been the vasopressor used most often in North America as it reliably prevents maternal hypotension, while mephentermine is used commonly in many Asian countries including India $[11,19]$. Conversely, ephedrine has been implicated in lower umbilical pH levels, especially when used in dosages high enough to stem nausea and vomiting related to hypotension [20,21]. Recent studies have indicated a decrease in side effects related to vasopressors, such as nausea and vomiting, and increased uteroplacental blood flow with the use of phenylephrine [17, 22]. Phenylephrine, an $\alpha$-agonist, has been found to be detrimental to the well-being of the fetus based on numerous animal models [16, $23,24]$. However, studies have begun to question the application of the results of animal models to human clinical practice due to physiological species differences $[16,22,25,26]$. The purpose of this study was to investigate the effectiveness and the side effects of intravenous phenylephrine and ephedrine in combating maternal hypotension resulting from spinal anesthesia in patients undergoing elective Cesarean section.

\section{Material and methods}

This study was performed at K.R. Hospital, Government Medical College, Rajiv Gandhi
University of Health Sciences (Karnataka state, India), during 2007-2008, after institutional approval was granted from the hospital's ethical and scientific committees. Informed consent was obtained from 100 female patients, ASA I/II status, scheduled for elective Cesarean section under spinal anesthesia.

\section{Study design}

Each patient was randomly assigned to one of the two double-blind study groups. The Group E received $1 \mathrm{ml}$ ephedrine, $50 \mathrm{mg}$ diluted to $10 \mathrm{ml}$ $(5 \mathrm{mg} / \mathrm{ml})$, with normal saline if hypotension was present. The Group $\mathrm{P}$ was given $1 \mathrm{ml}$ phenylephrine, $1 \mathrm{mg}$ diluted to $10 \mathrm{ml}(100 \mu \mathrm{g} / \mathrm{ml})$, with normal saline if hypotension was present. Blood pressure, oxygen saturation, pulse rate, and respiratory rate were monitored every $2 \mathrm{~min}$ for the first $10 \mathrm{~min}$, every $5 \mathrm{~min}$ from 10 to $30 \mathrm{~min}$ and every $15 \mathrm{~min}$ from 30 to $60 \mathrm{~min}$. Times of baby extraction, vasopressor administration and duration of surgery were recorded. Neonatal monitoring was performed by attending neonatologist at 1 and 5 min using APGAR scoring rubric [27].

\section{Pre-surgical protocol}

Prior to surgery each patient was examined and a thorough medical history taken with emphasis on respiratory and cardiovascular systems. Potential participants with diabetes mellitus, hypertension, pulmonary tuberculosis, drug allergies, bronchial asthma, epilepsy and bleeding disorders were excluded from the study. A history of pregnancyinduced hypertension and gestational diabetes, symptoms and signs of antepartum hemorrhage by placenta previa and abruption placenta were considered exclusion criteria. All patients received $10 \mathrm{ml} / \mathrm{kg}$ of ringer lactate for pre loading. Intraoperatively around 1000-1500 ml of normal saline was infused to the patients. In ephedrine group, $92 \%$ of patients received a total dose of $5 \mathrm{mg}$ of ephedrine (single bolus) and $8 \%$ of patients received a total dose of $10 \mathrm{mg}$ of ephedrine ( 2 boluses). In phenylephrine group, $94 \%$ of patients received a total dose of $100 \mu \mathrm{g}$ of phenylephrine (single bolus) and 6\% of patients received a total dose of $200 \mu \mathrm{g}$ of phenylephrine ( 2 boluses).

\section{Surgical protocol}

On the day of surgery, patients were premedicated with a single injection of metoclopramide $10 \mathrm{mg}$ and a single injection of ranitidine $50 \mathrm{mg}$ IV one hour prior to surgery. Both groups were pre-loaded with RL $10 \mathrm{ml} / \mathrm{kg} 20$ min before spinal anesthetic procedure. Patients were positioned in the right lateral position with flexion of thigh and legs, hip and knees and flexion at the 
head. The operating table was kept flat. Using aseptic precautions, lumbar puncture was performed at $\mathrm{L}_{3-4}$ using midline approach with $23 \mathrm{G}$ sterile Quinke's needle. After visualization of clear and free flow of cerebrospinal fluid (CSF), bupivacaine $0.5 \%$ heavy, $1.6 \mathrm{ml}$ bolus was injected into $\mathrm{L}_{3-4}$ subarachnoid space. Patients were turned to supine position with a wedge under the right buttock. After recording preoperative (basal) heart rate (HR), systolic blood pressure (SBP), diastolic blood pressure (DBP), mean arterial pressure (MAP), and $\mathrm{SPO}_{2}$ patients were monitored according to the protocol as indicated in the study design section. If hypotension occurred, defined as a fall of systolic blood pressure $\leq 90 \mathrm{~mm} \mathrm{Hg}$ and/or 30\% less than the basal SBP, patients were given either phenylephrine or ephedrine by anesthesiologist who was blinded about the drug in the syringe. Time of vasopressor administration, duration of surgery, and time of neonate extraction were recorded as minutes after start of surgery. All incidences of bradycardia $(\mathrm{HR}<60 \mathrm{bpm})$ were treated with atropine $0.5 \mathrm{mg}$ IV; any tachycardia (HR $>30 \%$ above the basal HR) was noted. Intraoperative nausea and vomiting were recorded. After baby extraction, all patients received 20 units oxytocin by infusion through a separate line. Neonatal well-being was assessed by attending neonatologist. Patients were monitored postoperatively for $24 \mathrm{~h}$ for adverse effects.

\section{Statistical analysis}

Summary statistics of age, weight, height for both "P" group and "E" group were reported as means \pm standard deviation. Intra- and inter-group analysis for HR, SBP, DBP, and MAP were statistically evaluated using one-way ANOVA and paired $t$-tests using both StatPlus ${ }^{\mathrm{TM}} \mathrm{V} 2$, and Minitab ${ }^{\mathrm{TM}}$, where $p<0.05$ was considered significant and $p<0.001$ highly significant. Complications of nausea, vomiting, tachycardia and bradycardia were evaluated with the Fisher's exact test, where $p<0.05$ was considered significant and $p<0.001$ highly significant.

\section{Results}

Overall, the demographic characteristics of both groups were similar. There were no statistical differences between the groups with respect to age, weight, or height (Table I). All patients required vasopressor therapy for hypotension. In our study, top-off doses of vasopressor for repeat hypotension were comparable between groups ( $6 \%$ in group $\mathrm{P}$, $8 \%$ in group $\mathrm{E})$. Decline from the basal heart rate was observed in phenylephrine $(P)$ group but was not significant across all measured times (Figure 1). An increase in heart rate from basal levels was seen in ephedrine (E) group across all times and this was significant at each time. The mean maximum heart rate recorded after vasopressor administration was

Table I. Demographic characteristics and operation data between groups

\begin{tabular}{|lccc|}
\hline & Ephedrine group means (SD) & Phenylephrine group means (SD) & $P$-value \\
\hline Age [years] & $24.08(3.74)$ & $23.38(3.54)$ & 0.169 \\
\hline Weight [kg] & $54.84(6.28)$ & $56.42(4.70)$ & 0.086 \\
\hline Height [cm] & $150.74(4.49)$ & $151.1(3.55)$ & 0.344 \\
\hline Duration of surgery [min] & $47.4(3.81)$ & $45.3(3.70)$ & $<0.001$ \\
\hline Time of baby extraction [min] & $6.24(2.06)$ & $6.28(2.94)$ & 0.45 \\
\hline
\end{tabular}

Data expressed as mean (SD)
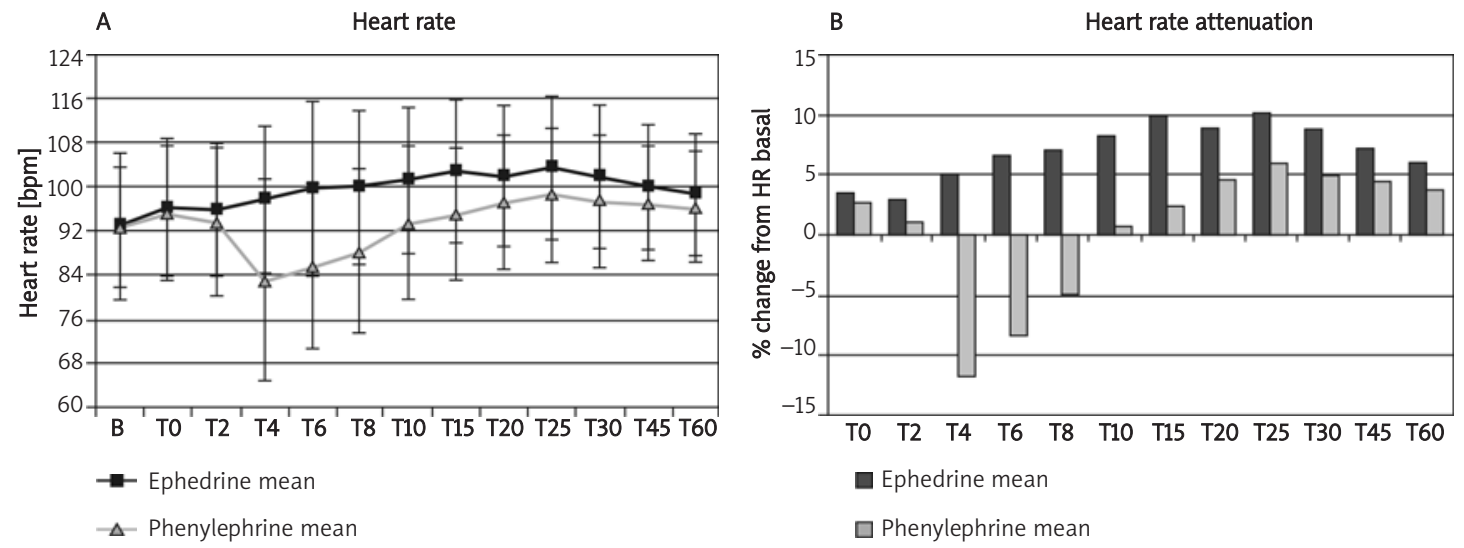

Figure 1. A - Mean heart rate $(H R)$ values for ephedrine and phenylephrine mean \pm SD, and $B$ - percent difference between measured HR levels and basal values 
Table II. Time of vasopressor administration and the following hemodynamic values between groups

\begin{tabular}{|lccc|}
\hline & Ephedrine group means (SD) & Phenylephrine group means (SD) & $P$-value \\
\hline $\begin{array}{l}\text { Time of vasopressor } \\
\text { administration [min] }\end{array}$ & $4.52(4.25)$ & $3.48(3.72)$ & $<0.05$ \\
\hline $\begin{array}{l}\text { Maximum HR after vasopressor } \\
\text { administration [beats/min] }\end{array}$ & $110.84(12.89)$ & $103.06(11.51)$ & $<0.05$ \\
\hline $\begin{array}{l}\text { Minimum HR after vasopressor } \\
\text { administration [beats/min] }\end{array}$ & $90.48(12.87)$ & $73.46(11.29)$ & $<0.001$ \\
\hline $\begin{array}{l}\text { Maximum SBP after vasopressor } \\
\text { administration [mm Hg] }\end{array}$ & $124.96(8.18)$ & $126.52(8.21)$ & 0.18 \\
\hline $\begin{array}{l}\text { Minimum SBP after vasopressor } \\
\text { administration [mm Hg] }\end{array}$ & $99.72(20.74)$ & $104.16(7.50)$ & 0.09 \\
\hline
\end{tabular}

Data expressed as mean (SD), HR - heart rate, SBP-systolic blood pressure

Table III. Mean heart rate values

\begin{tabular}{|lccc|}
\hline $\begin{array}{l}\text { Time } \\
{[\mathrm{min}]}\end{array}$ & $\begin{array}{c}\text { Ephedrine } \\
\text { group means } \\
\text { (SD) [beats/min] }\end{array}$ & $\begin{array}{c}\text { Phenylephrine } \\
\text { group means }\end{array}$ & P-value \\
\hline (SD) [beats/min] & \\
\hline 0 & $92.86(13.22)$ & $92.62(10.79)$ & 0.47 \\
\hline 2 & $96.14(12.42)$ & $95.22(12.12)$ & 0.36 \\
\hline 4 & $95.68(11.88)$ & $93.56(13.20)$ & 0.22 \\
\hline 6 & $97.62(13.38)$ & $82.86(18.23)$ & $<0.001$ \\
\hline 8 & $99.50(15.88)$ & $85.50(14.91)$ & $<0.001$ \\
\hline 10 & $99.84(13.98)$ & $88.30(14.69)$ & $<0.001$ \\
\hline 15 & $101.20(13.34)$ & $93.32(13.75)$ & $<0.005$ \\
\hline 20 & $102.86(12.96)$ & $94.98(11.76)$ & $<0.005$ \\
\hline 25 & $101.90(12.90)$ & $97.14(12.23)$ & $<0.05$ \\
\hline 30 & $103.00(12.90)$ & $98.54(12.10)$ & $<0.05$ \\
\hline 45 & $101.70(13.02)$ & $97.36(11.92)$ & 0.06 \\
\hline 60 & $100.00(11.42)$ & $96.88(10.37)$ & 0.10 \\
\hline Data are expressed as mean value (SD) & $96.76(11.05)$ & $96.18(10.03)$ & 0.12 \\
\hline
\end{tabular}

A

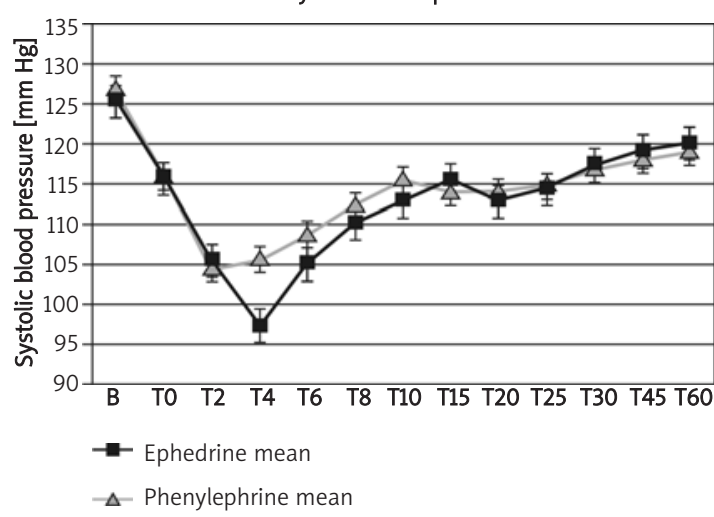

significantly higher in group $\mathrm{E}$ than in group $\mathrm{P}$ $(t=3.06, p<0.05)$ (Table 11$)$. Furthermore, administration of phenylephrine was associated with a highly significant drop in heart rate $(t=6.68$, $p \leq 0.001$ ) (Table III). Six patients in the P group required atropine for the treatment of bradycardia and responded favorably. The maximum and minimum systolic blood pressures after vasopressor bolus were higher in group $\mathrm{P}$, though the differences were not statistically significant. No significant difference in SBP between the groups was recorded at all measured points except at $T=4$ min (Figure 2), when SBP of patients in group E was significantly lower than SBP of patients in group $\mathrm{P}(t=-2.85, p<0.05)$. Diastolic blood pressure was comparable between the ephedrine and phenylephrine groups for all measured times except at $T=2 \mathrm{~min}$, when $\mathrm{P}$ group DBP was significantly lower than E group DBP $(t=2.53$, $p<0.05$ ) (Figure 2). Beginning at $T=4 \mathrm{~min}$, MAP values between the groups was similar and not significant $(p>0.05)$. Overall, phenylephrine was

Figure 2. A - Mean systolic blood pressure values for ephedrine and phenylephrine mean \pm SD and B - mean diastolic blood pressure values for ephedrine and phenylephrine mean \pm SD

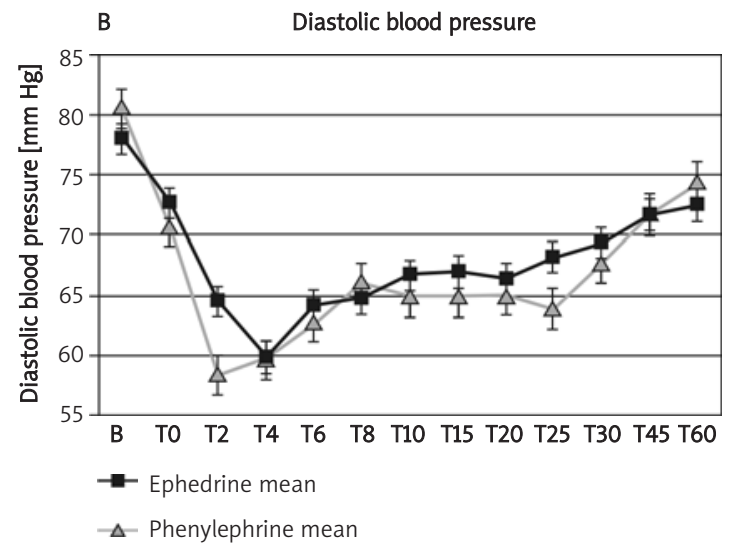


associated with a significantly higher increase in systolic blood pressure $(t=1.89, p<0.05)$ and mean arterial pressure $(t=1.92, p<0.05)$. In our study, 38 patients in ephedrine group and 36 patients in phenylephrine group had an upper level of sensory analgesia of $\mathrm{T}_{4-5}$. Twelve patients in ephedrine group and 14 patients in phenylephrine group had upper level of sensory analgesia of $\mathrm{T}_{6-7}$. The sensory level attained in both groups was therefore comparable and not significant $(p>0.08)$.

\section{Complications}

While 9 patients (18\%) in the ephedrine group exhibited nausea, only 4 patients (8\%) in the phenylephrine group experienced nausea (Table IV). In the ephedrine group, 7 patients (14\%) vomited, while none $(0 \%)$ exhibited this symptom in the phenylephrine group. The incidence of vomiting between groups is statistically significant $(p<0.05)$. The number of patients with bradycardia was higher in the phenylephrine group, however all patients with bradycardia responded well to atropine. The administration of phenylephrine caused bradycardia in $12 \%$ of patients which was not significant $(p>0.05)$, while ephedrine was seen to cause tachycardia in $16 \%$ of patients which was significant $(p<0.05)$ (Table IV). In ephedrine group only one patient had bradycardia and this patient had an upper sensory level of $T_{3}$. In Phenylephrine group six patients had bradycardia and these patients had level of $\mathrm{T}_{5-6}$.

\section{APGAR scores}

APGAR scores of all neonates were satisfactory at birth. All babies in "E" group had APGAR scores between 8-9 at $1 \mathrm{~min}$ and 10 at $5 \mathrm{~min}$. All babies in group "P" had APGAR scores between 8-9 at $1 \mathrm{~min}$ and 10 at $5 \mathrm{~min}$. The results were comparable for both groups.

\section{Discussion}

This study demonstrated that phenylephrine and ephedrine are comparable vasopressors when used to treat hypotension during an elective Cesarean section. The significant difference in heart rate between groups can primarily be attributed to the decline in heart rate associated with phenylephrine and the increase in heart rate associated with ephedrine. Despite the significant decline in heart rate observed with phenylephrine, it provided better attenuation of heart rate than ephedrine for all measured time points except $T=4 \mathrm{~min}$ and $T=6 \mathrm{~min}$. Bradycardia is usually seen with phenylephrine usage because of its well known $\alpha$-agonist properties [28]. The incidence of tachycardia was significantly higher in the ephedrine group, possibly due to difficulty in accurate titration of
Table IV. Number of complications between groups

\begin{tabular}{|lccc|}
\hline & $\begin{array}{c}\text { Ephedrine } \\
\text { group, } n(\%)\end{array}$ & $\begin{array}{c}\text { Phenylephrine } \\
\text { group, } n(\%)\end{array}$ & $P$-value \\
\hline Nausea & $9(18 \%)$ & $4(8 \%)$ & 0.08 \\
\hline Vomiting & $7(14 \%)$ & $0(0 \%)$ & $<0.05$ \\
\hline Bradycardia & $1(2 \%)$ & $6(12 \%)$ & 0.05 \\
\hline Tachycardia & $8(16 \%)$ & $0(0 \%)$ & $<0.05$ \\
\hline 5 min Apgar $<7$ & $0(0 \%)$ & $0(0 \%)$ & 1.0 \\
\hline
\end{tabular}

Data expressed as number of patients $(n)(\%)$

ephedrine because of its initial slow response and longer duration of action. Our results are in agreement with a number of other studies where significant tachycardia was observed with ephedrine usage [15, 28]. However, Loughery's et al. [29] found no cases of rebound hypertension with ephedrine, while Magalhaes et al. [30] reported comparable numbers of both bradycardia and reactive hypertension with ephedrine and phenylephrine. Furthermore, incidence of fetal tachycardia with ephedrine was reported significant in another study [11]. Though fetal heart rate was not measured in this study, the incidence of maternal tachycardia with ephedrine was significant.

Spinal anesthesia was associated with hypotension in all patients in both groups. However, nausea and/or vomiting occurred in only $8 \%$ of patients in the phenylephrine group compared to $18 \%$ of patients in the ephedrine group. Our results are in concurrence with a number of recent studies indicating a significantly higher incidence of nausea/vomiting with ephedrine usage [19, 22, 29]. Nevertheless, Magalhaes et al. [30] reported a higher prevalence of nausea/vomiting in patients who received phenylephrine compared to those who received ephedrine. In all cases, administration of a second dose of vasopressor resulted in occurrence of nausea and/or vomiting. Furthermore, the maximum drop in systolic blood pressure was higher in the phenylephrine group than the ephedrine group, yet fewer incidences of nausea/vomiting occurred. We calculated the maximum drop from one time interval to the next measured time interval for each patient, then grouped them by whether or not they had nausea/vomiting. This suggests that the vasopressor choice may be more significant than the level of hypotension in predicting side effects. In addition, only one patient had bradycardia in ephedrine group, this patient had an upper sensory level of $\mathrm{T}_{3}$, compared six patients in phenylephrine group; these patients had upper sensory level of $\mathrm{T}_{5-6}$. Thus the bradycardia observed in ephedrine group may be due to activation of Bain Bridge reflex and involvement of cardio acceleratory fibers. In phenylephrine group, the bradycardia may be due 
to combination of Bain Bridge reflex and reflex bradycardia due to administration of phenylephrine.

Many studies have attempted to determine the best vasopressor during spinal anesthesia in elective and non-elective Cesarean section using both animal and human subjects [15, 18-20, 24, 28, 30-33]. Ephedrine has been used as a primary vasopressor in obstetric patients for years based on its efficacy in returning maternal systolic blood pressure to a normal reading during spinal anesthesia during Cesarean section. Ephedrine indirectly raises blood pressure by increasing the release of norepinephrine [11]. Since the 1960s, several studies on chronically instrumented sheep have suggested that ephedrine is a better choice as a vasopressor than phenylephrine, mephentermine, methoxamine or metaraminol $[16,24,31$, 34]. In pregnant ewes, ephedrine has not been shown to decrease blood flow to the uterus. Additionally, use of ephedrine returned fetal cardiovascular hemodynamics to baseline after maternal hypotension in a sheep model [16] and may prevent fetal late decelerations [11]. However, a number of studies have identified a decrease in fetal umbilical $\mathrm{pH}$ after administration of ephedrine $[20,30]$. This again corroborates the conclusions drawn from extensive review article by Lee et al. [28] that fetal umbilical $\mathrm{pH}$ was lower in parturients who received ephedrine than in those who received phenylephrine. Furthermore, phenylephrine has been used for quite some time as an alternative agent for the treatment of hypotension after spinal anesthesia in Cesarean sections or in cases where ephedrine was ineffective [21, 33]. Animal models with compromised fetuses suggest that phenylephrine does not increase fetal lactate concentrations [16]. Extrapolation from animal studies must be carefully considered due to physiological species differences and pharmacological requirements. Human studies with uncompromised fetuses have not indicated a negative fetal or maternal outcome with phenylephrine use, as demonstrated by the comparable Apgar scores of the neonates. Vasopressor choice in non-elective Cesarean sections is still debatable. Phenylephrine was shown to be as effective as ephedrine in nonelective cases in one human study [26]. This differs from studies with sheep indicating compromised fetuses better tolerate ephedrine than phenylephrine [16, 24].

In conclusion, both ephedrine and phenylephrine in the bolus dose of $5 \mathrm{mg}$ and $100 \mu \mathrm{g}$ respectively can safely be employed to combat hypotension in patients undergoing elective lower segment Cesarean section under spinal anesthesia. Further studies should be considered to evaluate the incidence of fetal acidosis and comparative fetal hemodynamics as a result of treating maternal hypotension. In addition, though both vasopressors reliably raised maternal blood pressure, the clinical significance of tachycardia, bradycardia and intraoperative nausea and vomiting should not be overlooked.

\section{Acknowledgments}

This work was partially supported by Rajiv Gandhi University, India and partly funded by Roosevelt University Summer Grant Award to Dr. S. Chandra. Undergraduate research support for Jennifer Malinowski was provided through NSF STEP grant \# 0757053.

\section{References}

1. Sreevidya S, Sathiyasekaran BW. High caesarean rates in Madras (India): a population-based cross sectional study. BJOG 2003; 110: 106-11.

2. Sufang G, Padmadas SS, Fengmin Z, Brown J, Stones RW. Delivery settings and caesarean section rates in China. Bull World Health Organ 2007; 85: 755-62.

3. Smith GC, Cordeaux Y, White IR, et al. The effect of delaying childbirth on primary Cesarean section rates. PLoS Med 2008; 5: 1123-32.

4. Festin MR, Laopaiboon M, Pattanittum P, Ewens M, Henderson-Smart D, Crowther C. Caesarean section in four South East Asian countries: reasons for, rates, associated care practices and health outcomes. BMC Pregnancy Childbirth 2009; 9: 17.

5. Stamer UM, Wiese R, Stuber F, Wulf H, Meuser T. Change in anaesthetic practice for Caesarean section in Germany. Acta Anaesthesiol Scand 2005; 49: 170-6.

6. Enohumah KO, Imarengiaye CO. Factors associated with anaesthesia-related maternal mortality in a tertiary hospital in Nigeria. Acta Anaesthesiol Scand 2006; 50: 206-10.

7. Popham P, Buettner A, Mendola M. Anaesthesia for emergency caesarean section, 2000-2004, at the Royal Women's Hospital, Melbourne. Anaesth. Intensive Care 2007; 35: 74-9.

8. McDonnell NJ. Difficult and failed intubation in obstetric anaesthesia; an observational study of airway management and complications associated with general anaesthesia. Int J Obstet Anesth 2008; 17: 292-7.

9. Algert CS, Bowen JR, Giles WB, Knoblanche GE, Lain SJ, Roberts CL. Regional block versus general anaesthesia for caesarean section and neonatal outcomes: a population based study. BMC Medicine 2009; 7: 20.

10. Choi DH, Kim JA, Chung IS. Comparison of combined spinal epidural anesthesia and epidural anesthesia for Cesarean section. Acta Anaesthesiol Scand 2000; 44: 214-9.

11. Cleary-Goldman J, Negron M, Scott J, et al. Prophylactic ephedrine and combined spinal epidural. Obstet Gynecol 2005; 106: 466-72.

12. Gau-Yang C, Cheng-Deng K, Ming-Jie Y, Huey-Ming L, YuhShow T. Comparison of supine and upright positions on autonomic nervous activity in late pregnancy: the role of aortocaval compression. Anaesthesia 1999; 54: 215-9.

13. Hanss R, Ohnesorge H, Kaufmann M, et al. Changes in heart rate variability may reflect sympatholysis during spinal anaesthesia. Acta Anaesthesiol Scand 2007; 51: 1297-304.

14. Bobrow CS, Soothill PW. Causes and consequences of fetal acidosis. Arch Dis Child Fetal Neonatal Ed 1999; 80: F246-9. 
15. Cooper DW, Gibb SC, Meek T, et al. Effect of intravenous vasopressor on spread of spinal anaesthesia and fetal acid-base equilibrium. Br J Anaesth 2007; 98: 649-56.

16. Erkinaro T, Makikallio K, Acharya G, et al. Divergent effects of ephedrine and phenylephrine on cardiovascular hemodynamics of near-term fetal sheep exposed to hypoxemia and maternal hypotension. Acta Anaesthesiol Scand 2007; 51: 922-8.

17. Ngan Kee WD, Tam YH, Khaw KS, Ng FF, Critchley LA, Karmakar MK. Closed-loop feedback computer controlled infusion of phenylephrine for maintaining blood pressure during spinal anaesthesia for Caesarean section: a preliminary descriptive study. Anaesthesia 2007; 62: 1251-6.

18. Mohta M, Agarwal D, Gupta LK, Tyagi A, Gupta A, Sethi AK. Comparison of potency of ephedrine and mephentermine for prevention of post-spinal hypotension in caesarean section. Anaeth Intensive Care 2008; 36 : 360-4.

19. Kansal A, Mohta M, Sethi AK, Tyagi A, Kumar P. Randomized trial of IV infusion of ephedrine or mephentermine for management of hypotension during spinal anaesthesia for Caesarean section. Anaesthesia 2005; 60: 28-34.

20. Ngan Kee WD, Lau TK, Khaw KS, Lee BB. Comparison of metaraminol and ephedrine infusions for maintaining arterial pressure during spinal anesthesia for elective Cesarean section. Anaesthesiology 2001; 95: 307-13.

21. Ngan Kee WD, Khaw KS. Vasopressors in obstetrics: what should we be using? Curr Opin Anaesthesiol 2006; 19: 238-43.

22. Macarthur A, Riley ET. Obstetric anesthesia controversies: vasopressor choice for postspinal hypotension during Cesarean delivery. Int Anesthesiol Clin 2007; 45: 115-32.

23. Kim YH, Veille JC, Cho MK, et al. Chronic hypoxia alters vasoconstrictive responses of femoral artery in the fetal sheep. J Korean Med Sci 2005; 20: 13-9.

24. Erkinaro T, Kavasmaa T, Pakkila M, et al. Ephedrine and phenylephrine for the treatment of maternal hypotension in a chronic sheep model of increased placental vascular resistance. Br J Anaesth 2006; 96: 231-7.

25. Kiserud T, Ozaki T, Nishina H, Rodeck C, Hanson MA. Effect of NO, phenylephrine, and hypoxemia on ductus venosus diameter in fetal sheep. Am J Physiol Heart Circ Physiol 2000; 279: H1166-71.

26. Ngan Kee WD, Khaw KS, Lau TK, Ng FF, Chui K, Ng KL. Randomised double-blinded comparison of phenylephrine vs ephedrine for maintaining blood pressure during spinal anaesthesia for non-elective Caesarean section. Anaesthesia 2008; 63: 1319-26.

27. Apgar V. A proposal for a new method of evaluation of the newborn infant. Curr Res Anesth Analg 1953; 32: 260-7.

28. Lee A, Ngan Kee WD, Gin T. A quantitative, systematic review of randomized controlled trials of ephedrine versus phenylephrine for the management of hypotension during spinal anesthesia for Cesarean delivery. Anesth Analg 2002; 94: 920-6.

29. Loughrey JP, Walsh F, Gardiner J. Prophylactic intravenous bolus ephedrine for elective Caesarean section under spinal anaesthesia. Eur J Anaesthesiol 2002; 19: 63-8.

30. Magalhaes E, Goveia CS, Ladeira L, Nascimento B, Kluthcouski S. Ephedrine versus phenylephrine: prevention of hypotension during spinal block for Cesarean section and effects on the fetus. Rev Bras Anestesiol 2009; 59: 11-20.
31. James FM, Greiss FC, Kemp RA. An evaluation of vasopressor therapy for maternal hypotension during spinal anesthesia. Anesthesiology 1970; 33: 25-34.

32. Ngan Kee WD, Khaw KS, Ng FF. Prevention of hypotension during spinal anesthesia for Cesarean delivery. Anesthesiology 2005; 103: 744-50.

33. Reidy J, Douglas J. Vasopressors in obstetrics. Anesthesiol Clin 2008; 26: 75-88.

34. Ralston DH, Shnider SM, deLorimier AA. Effects of equipotent ephedrine, metaraminol, mephentermine, and methoxamine on uterine blood flow in the pregnant ewe. Anesthesiology 1974; 40: 354-70. 